\title{
THE ROLE OF N-ACETYLCYSTEINE IN THE TREATMENT OF OTITIS MEDIA WITH EFFUSION
}

\author{
Dhiaa Abdullah Fadhel ${ }^{\circledR}$, Isam M Al-Shareda*, Haider MS Al-Attar ${ }^{* *}$, \\ \& Ahmed A Alansary ${ }^{\#}$
}

${ }^{\circledR}$ MB,ChB, FICMS Otolaryngology, Basrah Teaching Hospital. ${ }^{*} \mathrm{MB}, \mathrm{ChB}$, FICMS, Professor of Otolaryngology, Dept. of Surgery, College of Medicine, University of Basrah. ${ }^{* *}$ MB,ChB, FICMS Specialist Otolaryngologist, Basrah Teaching Hospital, " $\mathrm{MB}, \mathrm{ChB}$, FICMS Consultant Otolaryngologist, Basrah Teaching Hospital, Basrah, IRAQ.

\begin{abstract}
Otitis media with effusion (OME) is a chronic accumulation of fluid within the middle ear cleft and sometimes the mastoid air cells system. The disease is more common among children. Surgical management is cost effective and carry complications from anaesthesia and surgical intervention. The condition can be resolved with high percentage by using mucopeptide breaking agent $\mathrm{N}$-acetylcysteine

The aim of this study is to evaluate the effect of $\mathrm{N}$-acetylcysteine on the resolution of otitis media with effusion in children.

Fifty seven children (107 ears) aged between 4-15 years with OME were included in this study. Patients underwent a thorough otorhinolaryngological examination and were divided into two groups; in the study group of 30 patients, $\mathrm{N}$-acetylcysteine was administered, and the control group of 27 patients did not receive this treatment.

Patient were followed-up at attendance, one month, two months and three months later with microscopical ear examination, tympanometric and pure tone audiometric examination.

Patients were 39 males (68.4\%) and 18 females (31.6\%), 50 of them were with bilateral and 7 with unilateral disease. Following the treatment, there was improvement in the hearing loss as air bone gap was decreased. This improvement was statically significant in comparing the study and control groups $(P$ value $=0.022)$. Number of ears with type $A$ tympanogram increased to a rate of $74 \%, 71 \%$ in the right and left ears respectively in the study group. This rate was statically significant in comparing with the control group $(P$ value $=0.014)$.

In conclusion, $\mathrm{N}$-acetylcysteine is effective in the treatment of children with OME as well as that $\mathrm{N}$-acetylcysteine has minimal side effect and can be used safely in patients who are medically unfit for general anaesthesia.

Keywords: Otitis media, effusion, children, N-acetylcysteine, mucopeptide breaking agent
\end{abstract}

\section{Introduction}

Otitis media with effusion (OME) is a chronic accumulation of fluid in the middle ear and sometimes in the mastoid air cells system without evidence of infection. Symptoms usually involve hearing loss or aural fullness but typically do not involve pain or fever ${ }^{1}$. The underlying causes for OME are; respiratory tract infections, acute otitis media and/or allergy, followed by mucous production in the middle ear. Other important factor is eustachian tube dysfunction due to mechanical obstruction or physiological interference with the mucous clearance ${ }^{2}$. Diagnosis of OME depends on history, pneumatic otoscopy, pure tune audiometry and tympanometry ${ }^{1}$. Treatment usually done by the following steps; watchful waiting, drugs like antibiotics, steroids, decongestants, mucolytic, antiinflammatories, and surfactant ${ }^{2}$. Others modalities of treatment are; hearing aid and surgery by adenoidectomy or myringotomy with or without ventilation tube insertion ${ }^{2}$. Surgery is contraindicated 
in patients who are medically unfit for general anaesthesia, only hearing ear, otitis externa and anatomical narrowing in the external auditory canal ${ }^{3}$. Nacetylcysteine is the acetylated derivative of the amino acid L-cysteine and has been used as a mucolytic agent as well as an antidote for hepatotoxicity due to acetaminophen overdose. More recently, animal and human studies have shown that $\mathrm{N}$-acetylcysteine is a powerful antioxidant $^{4}$. N-acetylcysteine effectiveness as a mucolytic agent results from its sulfhydryl group interacting with disulfide bonds in mucoproteins, with mucus subsequently being broken into smaller, less viscous units, in addition to stimulating ciliary action and the gastropulmonary vagal reflex, thereby clearing mucus from the airways ${ }^{5}$. Nacetylcysteine is generally safe and well tolerated even at high doses. The most common side effects associated with high oral doses are; nausea, vomiting, and oral administration is contraindicated in persons with active peptic ulcer. Infrequently, anaphylactic reactions due to histamine release occur and can consist of rash, pruritus, angioedema, bronchospasm, tachycardia, and changes in blood pressure ${ }^{5,6}$. N-acetylcysteine should be used with caution during pregnancy, and only if clearly indicated ${ }^{7}$. Oral administration of $\mathrm{N}$-acetylcysteine and charcoal at the same time is not recommended, as charcoal may cause a reduction in its absorption ${ }^{8}$. Oral dose for $\mathrm{N}$-acetylcysteine as a mucolytic agent is $300 \mathrm{mg} /$ day in children less than 14 years and $600 \mathrm{mg} /$ day in children more than 14 years in three dividing doses. The only contraindication is hypersensitivity to $\mathrm{N}$ acetylcysteine ${ }^{7}$.

\section{Patients and methods}

This prospective study was carried out in Otolaryngology Department, Basrah General Hospital from July 2015 to April 2016. Fifty seven children (107 ears) aged between 4-15 years. They were 39 males (68.4\%) and 18 females (31.6\%), 50 cases were with bilateral and 7 cases with unilateral OME.

The exclusion criteria include sensitivity to $\mathrm{N}$-acetylcestiene, previous ventilation tube placement, previous adenoidectomy, craniofacial malformations, non-patent nasal airway from gross septal deviation, nasal polyps or choanal atresia and noncompliance. According to these criteria, 17 cases were excluded for the following reasons: Noncompliance (8 cases), previous adenoidectomy (4 cases), previous ventilation tube placement (3 cases), and cleft palate ( 2 cases).

Informed consent was taken from each child's parents or close relatives regarding the explanation of the disease process, its complications, the treatment options and the side effects.

Detailed history and full otorhinolaryngological and microscopical examinations were done. Rinne and Weber's tests were done on cooperative patients. Pure tone audiometry was done at frequencies of $500 \mathrm{~Hz}, 1000 \mathrm{~Hz}, 2000$ $\mathrm{Hz}$ and $4000 \mathrm{~Hz}$. Hearing loss for each ear was calculated through the average of air-bone gap taken at $500 \mathrm{~Hz}, 1000 \mathrm{~Hz}$ and $2000 \mathrm{~Hz}$. Tympanometry was performed at the same time.

Patients were categorized into two groups: The study group including 30 patients received $\mathrm{N}$-acetylcysteine (trade name ALLES $\AA$ effervescent tablet) in a dose of $300 \mathrm{mg} /$ day for those aged less than 14 years, and $600 \mathrm{mg} /$ day for patients aged more than 14 years, the control group including 27 patients who did not receive any treatment but a watchful waiting.

Patient's assessment depended on ear examination, pure tone audiometry and tympanometry and was performed at the end of the first month, the second month, and the third month after the first visit of each patient. Data processing and analysis was carried out with Statistical Package for Social Sciences (SPSS) 
software version 17. A p-value $<0.05$ is considered statistically significant.

\section{Results}

A total of 57 patients (107 ears) with OME were included in this study. The age of the studied groups ranged from 4 to 15 years (mean $9 \pm 2.6$ years). The majority of the patients belonged to the age group 8-11 years $(49.1 \%)$ followed by $4-7$ years $(35.1 \%)$, and $12-15$ years $(15.8 \%)$, as shown in table I.

Table I: Age distribution in control and study groups.

\begin{tabular}{|l|l|l|l|l|l|l|}
\hline \multirow{2}{*}{$\begin{array}{l}\text { Age } \\
\text { Group }\end{array}$} & \multicolumn{2}{|l|}{ Control } & \multicolumn{2}{l|}{ Study } & \multicolumn{2}{l|}{ Total } \\
\cline { 2 - 7 } & No. & $\%$ & No. & $\%$ & No. & $\%$ \\
\hline $4-7$ & 9 & 33.3 & 11 & 36.7 & 20 & 35.1 \\
\hline $8-11$ & 14 & 51.9 & 14 & 46.6 & 28 & 49.1 \\
\hline $12-15$ & 4 & 14.8 & 5 & 16.7 & 9 & 15.8 \\
\hline Total & 27 & 100 & 30 & 100 & 57 & 100 \\
\hline
\end{tabular}

There was unequal male and female distribution; 39 patients $(68.4 \%)$ were males and 18 patients $(31.6 \%)$ were females as demonstrated in figure 1 .

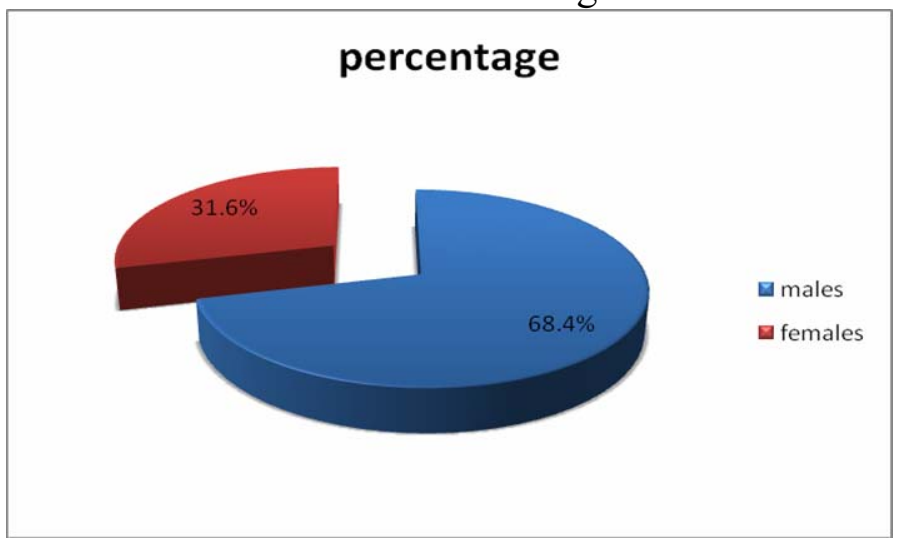

Figure 1: Gender distribution in all groups.

There was no great difference between the study and the control groups in regard to gender distribution (table II).

Table II: Gender distribution of study and control groups

\begin{tabular}{|l|l|l|l|l|l|}
\hline \multirow{2}{*}{ Parameters } & \multicolumn{2}{|c|}{ Study group } & \multicolumn{2}{l|}{ Control group } \\
\cline { 2 - 6 } & No. & $\%$ & No. & $\%$ \\
\hline \multirow{3}{*}{ Gender } & Male & 20 & 66.7 & 19 & 70.4 \\
\cline { 2 - 6 } & Female & 10 & 33.3 & 8 & 29.6 \\
\hline Total & 30 & 100 & 27 & 100 \\
\hline
\end{tabular}

The hearing was improved as the mean air-bone gap decreased. In the control group, the mean air-bone gap decreased in the right ears from $32.2 \mathrm{~dB}$ at attendance to $21.8 \mathrm{~dB}$ at the end of the third month, and from $32.2 \mathrm{~dB}$ to $22.9 \mathrm{~dB}$ in the left ears. In the study group, the mean air-bone gap decreased in the right ears from $32.1 \mathrm{~dB}$ at attendance to 18.5 $\mathrm{dB}$ at the end of the third month and from $29.1 \mathrm{~dB}$ to $18.2 \mathrm{~dB}$ in the left ears, as seen in table III. 
Table III: Mean hearing loss in control and study groups.

\begin{tabular}{|c|c|c|c|c|c|}
\hline \multicolumn{2}{|l|}{ Parameters } & \multicolumn{4}{|c|}{ Mean hearing loss in $\mathrm{dB}$} \\
\hline & & $\begin{array}{l}\text { Time of } \\
\text { attendance }\end{array}$ & $\begin{array}{l}1 \text { st } \\
\text { month }\end{array}$ & $\begin{array}{l}\text { 2nd } \\
\text { month }\end{array}$ & $\begin{array}{l}\text { 3rd } \\
\text { month }\end{array}$ \\
\hline \multirow[t]{2}{*}{ Control group } & Right & 32 & 26 & 23 & 21 \\
\hline & Left & 32 & 26 & 23 & 22 \\
\hline \multirow{2}{*}{$\begin{array}{l}\text { Study } \\
\text { group }\end{array}$} & Right & 32 & 25 & 20 & 18 \\
\hline & Left & 29 & 24 & 20 & 18 \\
\hline
\end{tabular}

Hearing loss difference between the control and study groups was non-significant at attendance in both right and left ears ( $\mathrm{P}$ value 0.971 and 0.098 respectively). The difference became significant at the third month in the right ears (P value 0.046), and at second month in the ears (P value 0.041), as shown in (table-4).

Table IV: P value of hearing loss difference.

\begin{tabular}{|l|l|l|l|l|}
\hline \multirow{2}{*}{ site } & \multicolumn{4}{|c|}{ P value } \\
\cline { 2 - 5 } & Attendance time & 1st month & 2nd month & 3rd month \\
\hline Right & 0.971 & 0.747 & 0.062 & 0.046 \\
\hline Left & 0.098 & 0.166 & 0.041 & 0.022 \\
\hline
\end{tabular}

There was an improvement in tympanometry results with decrease in type B in both control and study groups. Regarding study group, number of ears with type $\mathrm{B}$, tympanogram decreased from 22, 23 at attendance of right and left ears respectively to 2 in both ears at third month. In the control group, number of ears with type $\mathrm{B}$, tympanogram decreased from 19, 21 at attendance of right and left ears to 8,10 respectively as shown in table $\mathrm{V}$.

Table V: Tympanometry findings in the study and control groups.

\begin{tabular}{|c|c|c|c|c|c|c|c|c|c|}
\hline \multirow{2}{*}{\multicolumn{2}{|c|}{$\begin{array}{c}\text { Tympanogram } \\
\text { type }\end{array}$}} & \multicolumn{2}{|c|}{$\begin{array}{c}\text { Time of } \\
\text { attendance }\end{array}$} & \multicolumn{2}{|c|}{$\begin{array}{c}1^{\text {st }} \\
\text { month }\end{array}$} & \multicolumn{2}{|c|}{$\begin{array}{c}2^{\text {nd }} \\
\text { month }\end{array}$} & \multicolumn{2}{|c|}{$\begin{array}{c}3^{\text {rd }} \\
\text { month }\end{array}$} \\
\hline & & \multirow{2}{*}{$\begin{array}{c}\text { Rt } \\
\text { No. (\%) }\end{array}$} & \multirow{2}{*}{$\begin{array}{c}\text { Lt } \\
\text { No. }(\%)\end{array}$} & \multirow{2}{*}{$\begin{array}{c}\text { Rt } \\
\text { No. }(\%)\end{array}$} & \multirow{2}{*}{$\begin{array}{c}\text { Lt } \\
\text { No. }(\%)\end{array}$} & \multirow{2}{*}{$\begin{array}{c}\text { Rt } \\
\text { No. (\%) }\end{array}$} & \multirow{2}{*}{$\begin{array}{c}\text { Lt } \\
\text { No. }(\%)\end{array}$} & \multirow{2}{*}{$\begin{array}{c}\text { Rt } \\
\text { No. (\%) }\end{array}$} & \multirow{2}{*}{$\begin{array}{c}\text { Lt } \\
\text { No. }(\%)\end{array}$} \\
\hline & & & & & & & & & \\
\hline \multirow{3}{*}{$\begin{array}{l}\text { Study } \\
\text { group }\end{array}$} & Type B & $22(81.5)$ & $23(82.1)$ & $13(48.2)$ & $13(46.4)$ & $4(14.8)$ & $3(10.7)$ & $2(7.4)$ & $2(7.1)$ \\
\hline & Type C & $5(18.5)$ & $5(17.9)$ & $8(29.6)$ & $8(28.6)$ & $9(33.3)$ & $11(39.3)$ & $5(18.5)$ & $6(21.4)$ \\
\hline & Type A & $0(0)$ & $0(0)$ & $6(22.2)$ & $7(25)$ & $14(51.9)$ & $14(50)$ & $20(74.1)$ & $20(71.5)$ \\
\hline \multicolumn{2}{|c|}{ Total } & $27(100)$ & $28(100)$ & $27(100)$ & $28(100)$ & $27(100)$ & $28(100)$ & $27(100)$ & $28(100)$ \\
\hline \multirow{3}{*}{$\begin{array}{l}\text { Control } \\
\text { group }\end{array}$} & Type B & $19(76)$ & $21(77.8)$ & $13(52)$ & $15(55.6)$ & $9(36)$ & $10(37)$ & $8(32)$ & $10(37.1)$ \\
\hline & Type C & $6(24)$ & $6(22.2)$ & $8(32)$ & $8(29.6)$ & $10(40)$ & $10(37)$ & $7(28)$ & $6(22.2)$ \\
\hline & Type A & $0(0)$ & $0(0)$ & $4(16)$ & $4(14.8)$ & $6(24)$ & $7(26)$ & $10(40)$ & $11(40.7)$ \\
\hline \multicolumn{2}{|c|}{ Total } & $25(100)$ & $27(100)$ & $25(100)$ & $27(100)$ & $25(100)$ & $27(100)$ & $25(100)$ & $27(100)$ \\
\hline
\end{tabular}


Tympanometry results difference between the control and study groups was nonsignificant at attendance in both right and left ears ( $\mathrm{P}$ value 0.732 and 0.176 respectively). It became significant at the second month in both right and left ears ( $\mathrm{P}$ value 0.042 and 0.037 respectively) as shown in table VI.

Table VI: P value of tympanogram difference.

\begin{tabular}{|l|l|l|l|l|}
\hline \multirow{2}{*}{ Site } & \multicolumn{3}{|l|}{ P value } \\
\cline { 2 - 5 } & Attendance & 1st month & 2nd month & 3rd month \\
\hline Right & 0.732 & 0.509 & 0.042 & 0.013 \\
\hline Left & 0.176 & 0.176 & 0.037 & 0.014 \\
\hline
\end{tabular}

\section{Discussion}

Otitis media with effusion is quite common in children. It occurs after episodes of upper respiratory tract infection and resulting in hearing difficulty, behavioural and language developmental delay. Despite active intervention with antibiotics and ventilation tubes the disease has a marked tendency to recur, thus, a therapeutic strategy capable of reducing the frequency of recurrences is needed. $\mathrm{N}$ acetylcysteine is known to possess an anti-inflammatory, a mucolytic and antioxidant properties ${ }^{9}$.

The mean age in our study was $9 \pm 2.6$ years, similar to Mohammad et al study that showed a mean age $8.7 \pm 2.45$ years ${ }^{10}$. We found that, the most common affected age group was 8-11 years (49.1\%), this differs from Ashoor study, which showed decreasing OME incidence with increasing age, from $40 \%$ at 2 years to $1.4 \%$ at 11 years ${ }^{11}$. Many explanations for these results were; the differences in the nature of social life, like entry of children into kindergarten at which educational delay can detect early, this delay could be due to hearing impairment from OME, in addition to the massive screening performed to detect hearing difficulty at early childhood.

We found OME was more common in males $(68.4 \%)$ than females $(31.6 \%)$. Our finding is in agreement to Baharudin et al study, which showed $72 \%$ males and $28 \%$ females $^{12}$, and disagree with Boztepe et al study that showed $67 \%$ females and $33 \%$ males ${ }^{9}$.
There was significant improvement in hearing as the mean air-bone gap decreased, which was more prominent in the study group with statistically significant difference, $(\mathrm{P}$ value $=0.041)$ in the left ears during the second month, and $(P$ value $=0.046)$ in the right ears during the third month of the study. No similar study was found to use pure tone audiometry as a parameter to follow-up the patients. The difference in tympanometry results started in the first month, type A tympanogram increased to $74.1 \%$ in the right ears and $71.5 \%$ in the left ears during the third month. There was statistically significant difference in the second month in both right and left ears ( $\mathrm{P}$ value 0.042 and 0.037 respectively). This finding was in agreement with Boztepe et al study, who detect improvement in tympanometry results in the first month and recovery rate at third month $(84 \%, 87 \%$ in the right and the left ears respectively) ${ }^{9}$, and in agreement with Hayden FG study, who explain that the use of the $\mathrm{N}$ acetylcysteine in a double-blind, placebocontrolled study of 435 adults and children; benefits were recorded in terms of a change in the tympanogram at day 15 after the start of treatment ${ }^{1}$.

Conclusions: $\mathrm{N}$-acetylcysteine is effective in treating children with OME. No adverse events were reported in patients treated with $\mathrm{N}$-acetylcysteine, it can be used safely when surgery is contraindicated in patients who are medically unfit or unwilling for general 
anaesthesia. Children with OME treated by $\mathrm{N}$-acetylcysteine can gain improvement in the tympanometry results as early as the first month of the treatment. Children with OME treated by $\mathrm{N}$-acetylcysteine can gain rapid improvement in the hearing as the air bone gap rapidly decreases.

\section{References}

1. Browning G. Otitis media with effusion. In: Gleeson M, Browning G, Burton M J, Clarke R, Hibbert J, Jones N S, Lund V J, Luxon L M, Watkinson J C. Scott-Brown's Otorhinolaryngology, Head and Neck Surgery volume 1. 7th edition. London: Hodder Arnold; 2008. 72: 877-906.

2. Warner G, Burgess A, Patel S et al. Otitis media with effusion. In: Oxford specialist handbook in otolaryngology and head and neck surgery. 1st edition. Oxford: Oxford University Press; 2009. 16: 372-374.

3. Robb P J. Tympanostomy tube insertion. In: Bleach N, Milford C, Hasselt A V. Operative otorhinolaryngology. 1st edition. Oxford: Blackwell Science; 1997. 1: 32-37

4. Borgstrom L, Kagedal B, Paulsen O. Pharmacokinetics of N-acetylcysteine in man. Eur J Clin Pharmacol 1986 ; 31:217-222.

5. Zimet I. Acetylcysteine: A drug that is much more than a mucokinetic. Biomed Pharmacother $1988 ; 42: 513-520$.

6. Ovesen T, Felding JU, Tommerup B et al. Effect of N-acetylcysteineon the incidence of recurrence of otitis media with effusion and re-insertion of ventilation tubes. Acta Otolaryngol Suppl. $2000 ; 543: 79-81$.

7. Threlkeld DS, ed. Drug Facts and Comparisons. St Louis, Missouri: Facts and Comparisons; 1997:1090-1094.

8. Klein-SW, Oderda GM. Adsorption of oral antidotes for acetaminophen poisoning (methionine and $\mathrm{N}$-acetylcysteine)

9. Osman FB, Taylan G, Ozer EG et al Effect of N-acetylcysteinefor the treatment of otitis media with effusion J Med Updates 2014;4(1):20-24.

10. Mohammad WE, Ahmad AN, Alaa OK et al.The Efficacy of Nasal Steroids in Treatment of Otitis Media with Effusion. Int Arch Otorhinolaryngol. 2015 Oct; 19(4): 298-301

11. A. Ashoor Middle Ear Effusion in Children: Review of Recent Literature J Family Community Med. 1994 Jan-Dec; 1(1): 12-18.

12. Baharudin A, Shahid H, Dinsuhaimi S. Clinical and Audiological Profiles in Children with Chronic Otitis Media with Effusion Requiring Surgical Intervention: Malays J Med Sci. 2007 Jul; 14(2): 22-27. 